Efficient $\mathrm{Vol}$ 1 (2) (2018): 135-142. DOI: https://doi.org/10.15294/efficient.vii2.27616
Indonesian Journal of Development Economics
http: https://journal.unnes.ac.id/sju/index.php/efficient

\title{
Peran Pemerintah Kota Semarang dalam Meningkatkan Kesejahteraan Anak Melalui Dana APBD
}

\author{
Siska Veronika Nainggolan $^{1 凶}$, Y. Titik Haryati $^{2}$ \\ Jurusan Ekonomi Pembangunan,Fakultas Ekonomi, Universitas Negeri Semarang \\ Permalink/DOI: https://doi.org/10.15294/efficient.vii2.27616 \\ Received: January 2018; Accepted: March 2018; Published: Juny 2018
}

\begin{abstract}
This study aims to determine the government's efforts and the distribution of social funds in terms of improving the welfare of children in the of Semarang. Methods of collection data in the form of primary and secondary data. The study describes the Government Performance to reduce the number of abandoned children in Semarang. The results of the research analysis conclude as follows: Effort of Semarang Government performance through 15 OPD Child Response, Pattern of social fund distribution in improving children welfare in Semarang. Semarang Government has managed to improve the welfare of abandoned children, street children through programs / work activities that have been implemented.
\end{abstract}

Keywords: Problem of Neglected Children, Social Welfare, Fund Distribursement of Semarang City Budget

\begin{abstract}
Abstrak
Penelitian ini bertujuan untuk mengetahui upaya pemerintah dan penyaluran dana sosial dalam hal peningkatan kesejahteraan anak di Kota Semarang.Metode pengumpulan data berupa data primer dan sekunder. Penelitian mendeskripsikan tentang Kinerja Pemerintah untuk mengurangi jumlah anak terlantar di Kota Semarang. Hasil analisis penelitan menyimpulkan sebagai berikut: Upaya kinerja pemerintah Kota Semarang melalui 15 OPD Respon Anak, Pola penyaluran dana sosial dalam peningkatan kesejahteraan anak di Kota Semarang. Kesimpulan dari penelitian ini adalah Pemerintah Kota Semarang telah berhasil meningkatkan kesejahteraan anak terlantar, anak jalanan melalui program/ kegiatan kerja yang telah terlaksanakan.
\end{abstract}

Kata Kunci: Masalah Anak Terlantar, Kesejahteraan Sosial, Penyaluran Dana APBD Kota Semarang

How to Cite: Nainggolan, S., \& Haryati, Y. T. (2018). Peran Pemerintah Kota Semarang dalam Meningkatkan Kesejahteraan Anak Melalui Dana APBD. EFFICIENT Indonesian Journal of Development Economics, 1(2), 135 -142. https://doi.org/10.15294/efficient.vii2.27616

(c) 2018 Semarang State University. All rights reserved

\footnotetext{
Alamat Korespondensi :

Alamat: Gedung L2 Lantai 2 FE Unnes

Kampus Sekaran, Gunungpati, Semarang, 50229

E-mail : siskaveronika55@gmail.com
} 


\section{PENDAHULUAN}

Indonesia merupakan Negara berkembang yang memiliki jumlah penduduk yang selalu meningkat. Negara yang memiliki jumlah penduduk terbanyak di dunia adalah China di urutan pertama dengan jumlah penduduk mencapai 1.373.541.278 jiwa, urutan ke dua India dengan jumlah penduduk mencapai 1.266.883.594 jiwa, urutan ke tiga Amerika Serikat dengan jumlah penduduk 326.995.528 jiwa, dan urutan ke empat Indonesia dengan jumlah penduduk mencapai 258.316.051 jiwa.

Tabel 1. Negara yang memiliki jumlah penduduk terbanyak Tahun 2016(dalam ribuan)

\begin{tabular}{|c|c|c|}
\hline \multirow[t]{2}{*}{ No } & Nama Negara & Penduduk \\
\hline & & Tahun 2016 \\
\hline 1 & China & 1.373 .541 .278 \\
\hline 2 & India & 1.266 .883 .594 \\
\hline 3 & Amerika Serikat & $326.995 \cdot 528$ \\
\hline 4 & Indonesia & 258.316 .051 \\
\hline
\end{tabular}

Proyeksi BPS mengungkapkan, bahwa jumlah penduduk Indonesia tahun 2017 diperkirakan mencapai 261 juta jiwa. Ada beberapa provinsi yang merupakan provinsi berpenduduk terbanyak.

Urutan provinsi yang memiliki jumlah penduduk terbanyak di Indonesia adalah Provinsi Jawa Barat dengan jumlah penduduk mencapai 48 juta jiwa atau 18,34\%, urutan kedua yaitu Provinsi Jawa Timur mencapai 39,293 juta jiwa atau 15,00\%, urutan ke tiga Jawa Tengah mencapai 34,257 juta jiwa atau 13,08\% dan jumlah penduduk yang paling rendah adalah Provinsi Maluku Utara mencapai 1,209 juta jiwa atau 0,46\%, Provinsi Gorontalo mencapai 1,168 juta jiwa atau $0,45 \%$,Provinsi Papua Barat mencapai 915,400 ribu jiwa atau 0,35\%.
Tabel 2. Proyeksi Jumlah Penduduk Indonesia

\begin{tabular}{|c|c|c|c|}
\hline No & Provinsi & 2017 & $\%$ \\
\hline 1 & Jawa Barat & $48,037,600$ & $18,34 \%$ \\
\hline 2 & Jawa Timur & $39,293,000$ & $15,00 \%$ \\
\hline 3 & Jawa Tengah & $34,257,900$ & $13,08 \%$ \\
\hline 4 & Sumatera Utara & $14,262,100$ & $5,45 \%$ \\
\hline 5 & Banten & $12,448,200$ & $4,75 \%$ \\
\hline 6 & DKI Jakarta & $10,374,200$ & $3,96 \%$ \\
\hline 7 & Sulawesi selatan & $8,690,300$ & $3,32 \%$ \\
\hline 8 & Lampung & $8,289,600$ & $3,17 \%$ \\
\hline \multirow[t]{2}{*}{9} & Sumatera & $8,267,000$ & $3.16 \%$ \\
\hline & Selatan & & \\
\hline 10 & Riau & $6,657,900$ & $2,54 \%$ \\
\hline 11 & Sumatera Barat & $5,321,500$ & $2,03 \%$ \\
\hline \multirow[t]{2}{*}{12} & Nusatenggara & $5,287,300$ & $2,02 \%$ \\
\hline & Timur & & \\
\hline 13 & Aceh & $5,189,500$ & $1,98 \%$ \\
\hline \multirow[t]{2}{*}{14} & Nusatenggara & $4,955,600$ & $1,89 \%$ \\
\hline & Barat & & \\
\hline \multirow[t]{2}{*}{15} & Kalimantan & $4,932,500$ & $1,88 \%$ \\
\hline & Barat & & \\
\hline \multirow[t]{2}{*}{16} & Kalimantan & $4,266,500$ & $1,63 \%$ \\
\hline & Timur & & \\
\hline 17 & Bali & $4,246,500$ & $1,62 \%$ \\
\hline \multirow[t]{2}{*}{18} & Kalimantan & $4,119,800$ & $1,57 \%$ \\
\hline & Selatan & & \\
\hline 19 & DI Yogyakarta & $3,762,200$ & $1,44 \%$ \\
\hline 20 & Jambi & $3,515,000$ & $1,34 \%$ \\
\hline 21 & Papua & $3,265,200$ & $1,25 \%$ \\
\hline \multirow[t]{2}{*}{22} & Sulawesi & $2,966,300$ & $1,13 \%$ \\
\hline & Tengah & & \\
\hline \multirow[t]{2}{*}{23} & Kalimantan & $2,605,300$ & $0,99 \%$ \\
\hline & Tengah & & \\
\hline \multirow[t]{2}{*}{24} & Sulawesi & $2,602,400$ & $0,99 \%$ \\
\hline & Tengara & & \\
\hline 25 & Sulawesi Utara & $2,461,000$ & $0,94 \%$ \\
\hline 26 & Kep.Riau & $2,082,700$ & $0,74 \%$ \\
\hline 27 & Bengkulu & $1,934,300$ & $0,74 \%$ \\
\hline 28 & Maluku & $1,744,700$ & o,67\% \\
\hline \multirow[t]{2}{*}{29} & KEP.Bangka & $1,430,900$ & $0,55 \%$ \\
\hline & Belitung & & \\
\hline 30 & Sulawesi Barat & $1,331,000$ & $0,51 \%$ \\
\hline 31 & Maluku Utara & $1,209,3001$ & $0,46 \%$ \\
\hline
\end{tabular}




\begin{tabular}{llll}
\hline 32 & Gorontalo & $\mathbf{1 , 1 6 8 , 2 0 0}$ & $\mathbf{0 , 4 5 \%}$ \\
33 & Papua Barat & 915,400 & $0,35 \%$ \\
34 & Kalimantan & - & - \\
& Utara & & \\
& Total & $261,890,90$ & $100 \%$ \\
& & 0 &
\end{tabular}

Sumber: BPS Kota Semarang (2017)

Jumlah penduduk yang besar tidak selalu didukung dengan tingkat pemerataan perekonomian yang baik. Jumlah penduduk yang besar dapat menjadi salah satu tantangan bagi Indonesia karena dapat memberikan kesempatan kerja menjadi terbatas sehingga dapat menimbulkan kemiskinan. Kemiskinan dapat berdampak terhadap kesejahteraan sosial.

Hal ini akan menimbulkan berbagai masalah yang dapat dilihat dengan kasat mata misalnya tingkat kesejahteraan yang rendah di bidang sosial. Apabila kemiskinan meningkat maka kesejahteraan sosial juga akan menurun, dikarenakan kekurangan biaya kebutuhan sehari-hari dan pada akhirnya akan memunculkan masalah-masalah sosial.

Di sisi lain, ekonomi yang rendah akan memberikan dampak negatif bagi anak yang terpaksa akan ikut serta membantu dalam pemenuhan kebutuhan kehidupan sehari-hari (Sinabutar \& Setianingsih, 2015). Sinabutar dan Setianingsih (2015) menyatakan bahwa anakanak seharusnya mendapatkan perlindungan, bimbingan dan perhatian orang tua, mendapatkan pendidikan yang layak, melakukan sosialisasi dengan teman-teman. Namun pada kenyataannya, hal ini tidak sesuai dan masih terdapat perlakuan yang menyimpang, seperti

misalnya menelantarkan anak dan mempekerjakan anak di jalanan.
Menteri Sosial Khofifah Indar Parawansa menyatakan bahwa 4,1 juta anak Indonesia yang terlantar dan 35.000 anak yang dieksploitasi yang sangat membutuhkan perlindungan (Kompas, 2016). Komisi Perlindungan Anak Indonesia menyebutkan ada 18.000 anak yang merupakan korban eksploitasi (Kompas, 2016). Menteri Sosial menyatakan, masalah kesejahteraan sosial harus lebih diperhatikan terkhusus nasib dan masa depan anak-anak indonesia. Menteri Sosial juga menjelaskan bahwa pada tahun 2015 Kementerian Sosial memberikan pelayanan terhadap 2.00o anak jalanan di enam rumah perlindungan sosial anak di seluruh Indonesia (Kompas, 2016).

Provinsi Jawa Tengah merupakan salah satu provinsi yang memiliki jumlah penduduk paling banyak dan berada di no urutan ke 3 dan Jawa Tengah juga merupakan provinsi yang memiliki jumlah anak terlantar yang cukup tinggi. Dinas sosial Provinsi Jawa Tengah mengungkapkan jumlah anak terlantar di Tahun 2013 mencapai 80,009 orang, pada Tahun 2014 jumlah anak terlantar menurun dengan jumlah 66,565 orang, sedangkan pada Tahun 2015 jumlah anak terlantar meningkat hingga mencapai 120,181 orang (Dinas Sosial Kota Semarang, 2013, 2014, 2015).

Sisi lain, Provinsi Jawa Tengah memiliki jumlah anak jalanan yang tidak terlalu besar. Jumlah anak jalanan di jawa tengah pada Tahun 2013 mencapai 3,653 orang, Tahun 2014 menurun mencapai 3,477 orang dan pada tahun 2015 turun drastis sampai mencapai 1,603 orang (Dinas Sosial Kota Semarang, 2013, 2014, 2015). Perbandingan jumlah anak terlantar dengan anak jalanan sangat jauh berbeda. 
Wilayah Provinsi Jawa Tengah memiliki 29 Kabupaten dan 6 Kota dan salah satuya adalah Kota Semarang. Kota Semarang merupakan Ibukota Provinsi Jawa Tengah yang tidak lepas dari masalah sosial terutama masalah anak. sebagai salah satu masalah sosialnya adalah anak terlantar dan anak jalanan.

Pada Tahun 2011 memiliki populasi Anak Jalanan sebanyak 204 orang yang terdiri laki-laki 153 orang dan perempuan 51 orang. Pada Tahun 2012 memiliki popolasi anak jalanan 74 oang yang terdiri laki-laki 60 orang dan perempuan 14 orang (Dinas Sosial Kota Semarang, 2013, 2014, 2015). Pada Tahun 2011 memiliki populasi anak terlantar sebanyak 357 orang diantaranya laki-laki sebanyak 210 orang dan perempuan 147 orang. Sedangkan pada Tahun 2012 populasi anak terlantar sebanyak 116 orang diantarnya laki-laki sebanyak 64 orang dan perempuan 52 orang.

Sementara itu keberadaan anak jalanan (anjal) dan pemgemis, gelandangan, orang terlantar (PGOT) di Kota Semarang setiap tahun terus mengalami peningkatan. Di tahun 2012 tercatat sebanyak 270 anjal dan PGOT. Jumlah tersebut meningkat dua tahun setelahnya, yakni Tahun 2013 sebanyak 350 orang, sementara Tahun 2014 menjadi 400-an. Untuk Tahun 2015 jumlahnya diprediksi jauh lebih banyak mengingat selama Ramadan tahun itu saja sudah ada 197 anjal dan PGOT yang terkena razia Satpol PP Kota Semarang (Tribun Semarang, 2015).

Menurut Undang-undang No.23 Tahun 2002 anak adalah seseorang yang belum berusia 18 tahun, baik termasuk dalam kandungan yang memiliki hak atas hidup dan merdeka serta mendapatkan perlindungan yang baik dari orangtua dan masyrakat. Menurut Undangundang No.23 Tahun 2002 Pasal 1 Ayat 6 anak terlantar adalah anak yang tidak memiliki orangtua dan yang tidak terpenuhi kebutuhannya secara wajar baik fisik, mental, spiritual, maupun sosial.

Menurut Undang-undang No.23 Tahun 2002 Pasal 1 Ayat 2 perlindungan anak adalah segala kegiatan yang menjamin dan melindungi anak-anak dan hak-hak agar hidup, tumbuh kembang dan partisipasi secara optimal sesuai dengan harkat dan martabat kemanusiaan serta mendapatkan perlindungan dari kekerasan dan diskriminasi.

Menurut Undang-undang No.11 Tahun 2009 kesejahteraan sosial adalah kondisi terpenuhi kebutuhan material, spiritual dan sosial warga Negara agar hidup layak dan mampu mengembangkan diri sehingga mampu melaksanakan fungsi sosialnya.

Anggaran pendapatan dan belanja daerah (APBD) adalah dasar pengelolaan keunagan daerah dalam masa satu tahun anggaran terhitung dari 1 Januari sampai 31 Desember. Menurut Undang-undang No.32 Tahun 2004 APBD adalah rencana keuangan pemerintah daerah yang tetap dengan peraturan daerah.

Keterkaitannya dengan ekonomi dapat dilihat dari jumlah pertumbuhan penduduk, tingkat pendapatan ekonomi suatu daerah, kebijakan pemerintah Kota Semarang dalam tingkat kesejahteraan anak, dan tingkat responden dalam pelaksanaan kinerja

pemerintah Kota Semarang dengan menggunakan Anggaran Dana Sosial yang diterima oleh setiap 15 OPD di Kota Semarang.

Dengan menganalisis berbagai cara yang telah dilakukan, maka diketahui kekuatan (Strength), kelemahan (weakness), ancaman (threats). Kekuatan akan menjadi faktor pendukung penanganan masalah anak terlantar dan anak jalanan, faktor kelemahan dan ancaman akan menjadi faktor penghambat dalam penanganan kesejahteraan sosial anak di Kota 
Semarang. Ada 2 faktor yang mempengaruhi penanganan kesejahteran sosial anak tersebut yaitu yang pertama yaktor pendukung, faktor pendukung merupakan salah satu faktor yng menjadi penyebab kelancaran dan suksesnya program dan strategi yang dijalani oleh Dinas Sosial Kota Semarang. Uraian mengenai faktor pendukung tersebut dapat menjadi alat dalam penangan masalah kesejahteraan sosial terkhusus bagi anak-anak yang terlantar diantaranya (a) perhatian orangtua merupkan salah satu pendukung penangan masalah kesejahteraan sosial anak tersebut, (b) terlaksananya program-program dan strategi Dinas Sosial Kota Semarang dalam penanganan anak-anak dalam penanganan anak-anak terlantar dan anak-anak jalanan, (c) adanya kerja sama yang baik antara pemerintah Kota Semarang dengan Dinas Sosial Kota Semarang.

Kedua, faktor-faktor penghambat, faktor penghambat ini merupakan salah satu ancamanancaman dari lingkungan serta kelemahankelemahan dari perhatian-perhatian keluarga. Uraian mengenai faktor penghambat tersebut dapat dijelaskan diantaranya (a) kualitas sumber daya manusianya kurang bersahabat, (b) minimnya anggaran yang diterima Dinas Kurang kepedulian masyarakat sekitar terhadap anakanak, (c) kurang harmonis di tengah keluarga.

Oleh karena itu, tujuan dari penelitian ini adalah untuk mengetahui bagaimana upaya kinerja Pemerintah Kota Semarang dalam meningkatkan kesejahteraan anak dan untuk mengetahui pola penyaluran dana sosial dalam hal peningkatan kesejahteraan anak di Kota Semarang.

\section{METODE PENELITIAN}

Metode penelitian kualitatif deskriptif untuk menentukan cara mencari, mengumpulkan, mengolah, dan menganalisis data hasil penelitian tersebut. Penelitian ini mendeskripsikan tentang bagaimana peran pemerintah Kota Semarang dalam meningkatkan kesejahteraan sosial melalui Dana APBD Kota Semarang. Untuk memahami hal tersebut, perlu diteliti secara mendalam mengenai kriteria masalah kesejahteraan sosial anak terkhusus anak terlantar dan anak jalanan di Kota Semarang. Penelitian ini menggunakan studi kasus yang melihat fenomena mengenai masalah kesejahteraan anak terlantar dan anak jalanan di Kota Semarang. Studi kasus dilakukan untuk mengetahui apa faktor penyebab anak terlantar dan anak jalanan lebih memilih hidup di jalanan, serta mengetahui bagaimana upaya pemerintah Kota Semarang menangani peningkatan jumlah anak terlantar dan anak jalanan di Kota Semarang melalui Dana APBD Kota Semarang, dan mengetahui penyaluran Dana APBD Kota Semarang untuk mengurangi Jumlah anak terlantar dan anak jalanan di Kota Semarang.

Fokus penelitian sebagai wahana membatasi studi, agar masalah sosial anak ini dapat dipahami secara tepat, maka penulis harus menggunakan strategi dan konsep yang menjadi cara pemerintah dalam penanganan masalah sosial anak di Kota Semarang.

Penelitian ini dilakukan di 2 Lokasi di Kota Semarang, yang pertama yaitu: Dinas Sosial Kota Semarang, Rumah Rehabilitas Among Jiwo Kota Semarang, Panti Asuhan AL-Hikmah. 
Pemilihan lokasi dilakukan dengan beberapa alasan yaitu: Dinas Sosial Kota Semarang: mencari data jumlah anak terlantar dan anak jalanan di Kota Semarang, mencari berapa Dana APBD yang di terima dari pemerintah.

Kedua yaitu, Rumah Rehabilitas Among Jiwo merupakan tempat orang-orang yang memiliki masalah terhadap kejiwaan, akan tetapi rumah rehabilitas among jiwo juga menjadi tempat penyaluran anak terlantar dan anak jalanan yang di razia oleh Dinas Sosial Kota Semarang sebelum diserahkan ke panti-panti asuhan.

Informan dalam penelitian ini dapat di peroleh dari Tri Waluyo sebagai Kepala Rehabilitas Sosial. Informan pendukung dalam penelitian ini akan diperoleh dari Merdiah sebagi Satuan Bakti Pekerja Sosial, Nursiyah Sebagai Ketua Panti Asuhan Al- Hikmah, Diono sebagai Kepala Rehabilitas Among Jiwo.

Metode pengumpulan data merupakan cara yang digunakan peneliti untuk mendapatkan data dalam suatu penelitian. Data yang dikumpulkan meliputi data primer dan data sekunder. Data primer tersebut diperoleh dari pengamatan langsung peneliti sendiri, yakni hasil wawancara 7 informan, yang terdiri atas: 3 informan yang bersangkutan dengan Dinas Sosial, 1 informan merupakan Ketua Panti Asuhan Al- Hikmah, dan 3 informan merupakan anak jalanan. Sedangkan data sekunder dalam penelitian ini diperoleh dari dinas-dinas di Kota Semarang, Adapun metode pengumpulan data dalam penelitian ini adalah sebagai berikut: Wawancara, Dokumentasi, Obsevasi.

Penelitian menggunakan validasi data dengan melakukan pengujian terhadap keabsahan data dengan melakukan pengujian terhadap data menggunakan teknik triangulasi data. Teknik Triangulasi adalah teknik melakukan keabasahan data yang memanfaatkan sesuatu yang lain diluar data untuk keperluaan pengecekan atau pembandingan terhadap data tersebut.

Teknik Analisis Data yang digunakan dalam penelitian ini diantaranya adalah Data Reduction/Reduksi data, Data display/Penyajian data dan Conclusion drawing/verification (Verifikasi/Penarikan Kesimpulan).

\section{HASIL DAN PEMBAHASAN}

Beberapa pandangan menyatakan bahwa tingkat kesejahteraan seseorang sangat terkait dengan tingkat kepuasan dan kesenangan yang dapat diraih dalam kehidupannya. Guna mencapai tingkat kesejahteraan yang diinginkan, dibutuhkan perilaku (behavioral) yang dapat memaksimalkan tingkat kepuasannya sesuai sumber daya yang tersedia. Tingkat kesejahteraan masyarakat menengah kebawah dapat direpresentasikan dari tingkat hidup masyarakat. Tingkat hidup masyarakat ditandai oleh terentaskannya kemiskinan, tingkat kesehatan yang lebih baik, perolehan tingkat pendidikan yang lebih tinggi, dan peningkatan tingkat produktivitas masyarakat. Salah satu tolak ukur yang digunakan dalam melihat kualitas hidup manusia adalah dengan Indeks Pembangunan Manusia (IPM) atau yang dikenal dengan Human Development Index (HDI) yang dikeluarkan oleh United Nations Development Programme (UNDP). Indikator kesejahteraan masyarakat yang disusun oleh UNDP diukur melalui kualitas tingkat pendidikan, kesehatan dan ekonomi (daya beli). Melalui peningkatan ketiga indikator tersebut diharapkan akan terjadi peningkatan kualitas hidup manusia.

Berdasarkan indikator efektifitas upaya kinerja pemerintah Kota Semarang dapat 
diketahui melalui program-program/ kegiatan kerja, maka dapat diambil sampel melalui beberapa program/ kegiatan yang berpengaruh terhadap kesejahteraan anak di Kota Semarang.

Berdasarkan hasil analisis data dan informasi yang diterima, maka indicator program/ kegiatan dapat diukur dari (1) Tingkat Responden Terhadap Pelaksanaan Program/ Kerja, (2) Melalui tingkat reaksi dari kegiatan ini dapat dilihat, mengenai cara mendapatkan bantuan dana, responden menilai bahwa untuk mendapatkannya mudah serta waktu pengurusan untuk mendapatkan bantuan dana dari Negara maupun Donatur-donatur yang peduli akan kesejahteraan anak, (3) Tingkat Perilaku Responden dalam Upaya Pelaksanaan Kinerja Pemerintah Kota Semarang, (4) Melalui tingkat perilaku responden dari program/ kegiatan yang terlaksana dapat dilihat dari Anggaran Dana Sosial yang diterima yaitu, Rp. 1.494.085.00o pertahun dan Rencana Anggaran Kas sebesar Rp. 116.250.0oo. Penyaluran dana tersebut merupakan biaya kegiatan peningkatan kualitas pelayanan kesejahteraan bagi PMKS. Namun, dana yang diperoleh responden tersebut dijadikan uang tambahan oleh responden dalam hal untuk kebutuhan dasar sekolah dan (5) Tingkat Dampak dari Program/Kegiatan Kinerja Pemerintah Kota Semarang. Melalui tingkat ini, dapat dilihat dari bentuk kegiatan yang dilakukan oleh responden bervariasi.

Namun, setiap OPD merancang sebuah program/ kegiatan yang mendukung kesejahteraan anak di Kota Semarang akan tetapi tidak berjalan dengan baik, dikarenakan anak maupun orangtua susah diajak kerjasama oleh tiap Dinas. Justru anak lebih memilih berdagang, berdagang merupakan jumlah terbanyak yang dilakukan oleh responden, antara lain : - Dagang
Koran - Dagang Asongan, pengamen, dan lainlain. Bantuan dana yang diberikan oleh pemerintah tidak digunakan untuk hal pribadi, selain kebutuhan sekolah. Melainkan digunakan untuk kebutuhan dasar sekolah anak.

\section{SIMPULAN}

Berdasarkan hasil penelitian dan hasil pembahasan tentang Peran Pemerintah Kota Semarang dalam meningkatkan kesejahteraan sosial melalui Dana APBD Kota Semarang.

Beberapa pandangan menyatakan bahwa tingkat kesejahteraan seseorang sangat terkait dengan tingkat kepuasan dan kesenangan yang dapat diraih dalam kehidupannya. Guna mencapai tingkat kesejahteraan yang diinginkan, dibutuhkan perilaku (behavioral) yang dapat memaksimalkan tingkat kepuasannya sesuai sumber daya yang tersedia.

Berdasarkan hasil data dan informasi yang diterima, maka indikator program/ kegiatan dapat diukur dari (1) Tingkat Responden Terhadap Pelaksanaan Program/ Kerja. (2) Tingkat Perilaku Responden dalam Upaya Pelaksanaan Kinerja Pemerintah Kota Semarang.

(3) Tingkat Dampak dari Program/Kegiatan Kinerja Pemerintah Kota Semarang.

\section{DAFTAR PUSTAKA}

Dinas Sosial Kota Semarang. 2013,. 2014,. 2015. Jumlah Anak Terlantar. Semarang. Bidang Rehabilitas Anak.

Dinas Sosial Kota Semarang. 2014. Jumlah Anak Terlantar. Semarang. Bidang Rehabilitas Anak.

Dinas Sosial Kota Semarang. 2015. Jumlah Anak Terlantar. Semarang. Bidang Rehabilitas Anak.

Kompas. 2016. Perlindungan Anak Korban Eksploitas. 13 Mei. Pukul 12:21.

Sinabutar, M., \& Setianingsih, L. 2015. Pengawasan terhadap Penanganan Anak Jalanan Dinas Sosial dan Olahraga di Kota Semarang. Jurnal Ilmu Sosial dan Ilmu Politik, Hal 1-13 Kota Semarang: UNDIP. 
Undang-undang Republik Indonesia Nomor 23Tahun 2002 Pasal 1 Ayat 6 tentang Pengertian Anak Terlantar.

Undang-undang Republik Indonesia Nomor 23 Tahun 2002 Pasal 1 Ayat 2 tentang Perlindungan Anak.

Undang-undang Republik Indonesia Nomor 11Tahun 2009 tentang Kesejahteraan Sosial.

Undang-undang Republik Indonesia Nomor 32 Tahun 2003 tentang Pengerti Anggaran Pendapatan dan Belanja Daerah (APBD).

Undang-undang Republik Indonesia Nomor 33 Tahun 2004 tentang Pemerintah Daerah. 